\title{
Uma perturbadora encenação da história
}

\author{
Maria Helena Serôdio
}

A tragédia de Júlio César, de William Shakespeare, enc. Luis Miguel Cintra, Teatro da Cornucópia/ São Luis Teatro Municipal, 2007 (atrás: Luis Lima Barreto, Rita Durão e Teresa Sobral; à frente: Luis Miguel Cintra e Nuno Lopes), fot. Paulo Cintra.

Rui Pina Coelho, "Processo trágico em curso", Público 2, 27 de Março de 2007, p. 13.

${ }^{2}$ As outras peças que fazem também uso de aspectos da história de

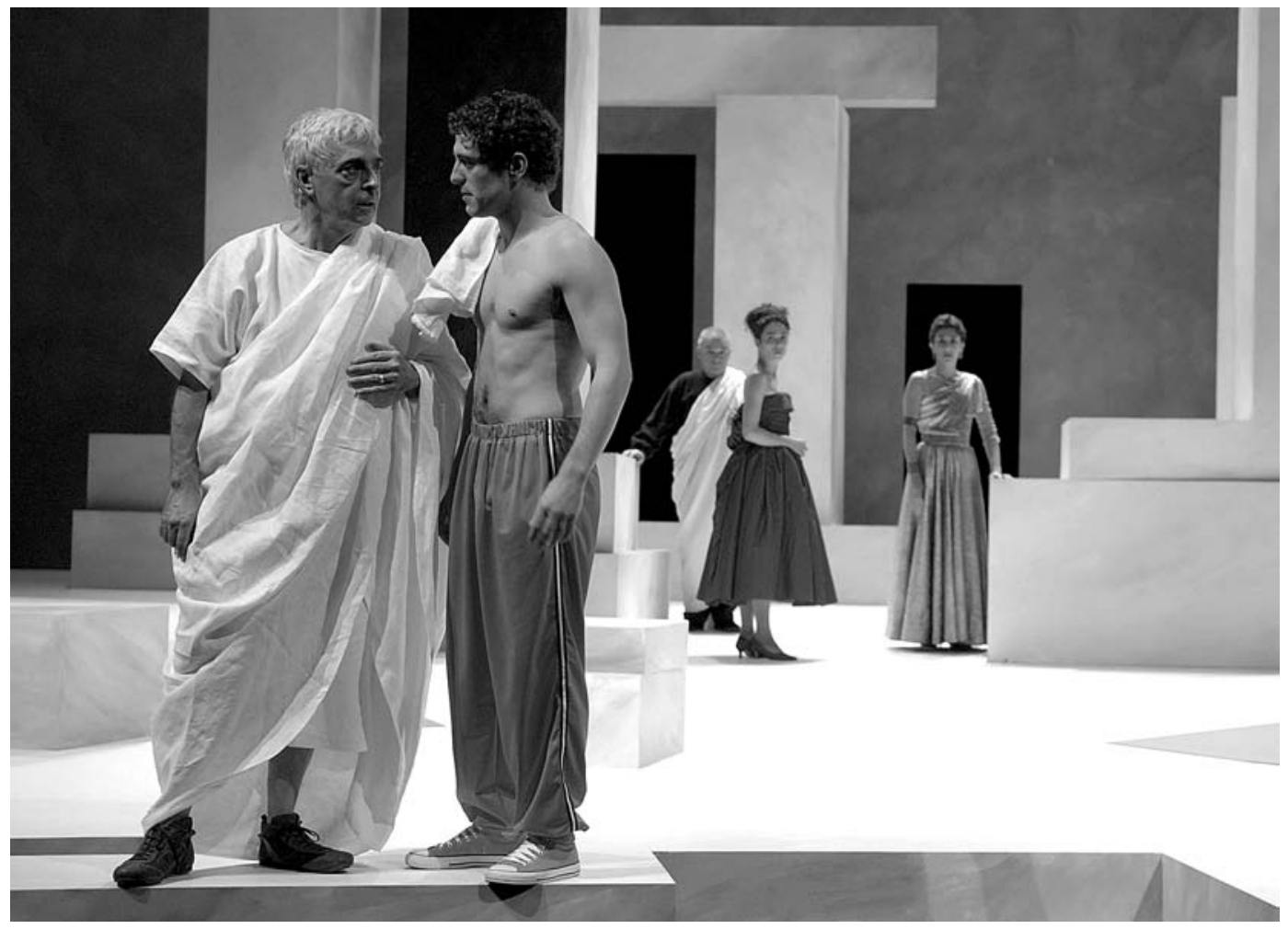

Título: A tragédia de Júlio César (The Tragedy of Julis Caesar,1599). Autor: William Shakespeare. Tradução: José Manuel Mendes, Luis Lima Barreto e Luis Miguel Cintra. Encenação: Luis Miguel Cintra. Cenários e figurinos: Cristina Reis. Desenho de luzes: Daniel Worm d'Assumpção. Música original: Vasco Mendonça. Músicos: Gonçalo Marques, Marco Santos e Nuno Santos. Interpretação: André Silva, Dinarte Branco, Dinis Gomes, Edgar Morais, Filipe Costa., Hugo Tourita, Ivo Alexandre, Joaquim Horta, José Manuel Mendes, Luis Lima Barreto, Luis Miguel Cintra, Luis Lucas, Martim Pedroso, Nuno Lopes, Nuno Gil, Pedro Lacerda, Pedro Lamas, Ricardo Aibéo, Rita Durão, Teresa Sobral, Tiago Matias, Tónan Quito e Vitor de Andrade. Co-Produção: São Luiz Teatro Municipal e Teatro da Cornucópia. Local e data de estreia: São Luiz Teatro Municipal, Lisboa, 21 de Março de 2007.

Como bem recorda Rui Pina Coelho no jornal Público', embora esta encenação pela Cornucópia seja a primeira que se faz em Portugal da tragédia romana por excelência de Shakespeare ${ }^{2}$ - e isso é, já em si, um caso digno de nota -, houve quem, em 1964, tivesse tentado levá-la à cena, seguramente para, entre outras razões, participar no que eram então as comemorações dos quatrocentos anos do nascimento do autor. Foi, de facto, o Teatro do Ateneu de Coimbra que se aventurou por esse desejo, mas não obteve a necessária aprovação da censura, pelo não foi possivel tal cometimento ${ }^{3}$.

Se a censura fascista lia, assim, na peça sinais de inquietante instigação à acção política, o mesmo ocorria, embora com uma razão e um desfecho inversos, por exemplo, nos círculos sindicais da Inglaterra, como bem documenta o livro de Raphael Samuel sobre as actividades politicas de diversas associações de trabalhadores na Grã Bretanha e na América ao longo do século XIX e inícios do século XX (Samuel 1985). Considerando a peça como "um poderoso drama político, e não um divertimento" (Ibidem: 7), esses activistas viam nela importantes modelos populares de actuação heróica, e em muitos casos terão usado expressões da peça como formas de chamamento ao dever ou até como discursos em funerais de dirigentes operários, como foi o caso de Ramsay MacDonald no do socialista escocês (dirigente do sindicato dos mineiros que chegou a Membro do Parlamento) Keir Hardie em 1915, usando partes do célebre discurso de Marco António. 
0 assassínio de César é, de todos os pontos de vista, um acto político de extrema gravidade e são expressivas as palavras que Shakespeare usa para o tornar emblemático de muitos outros que ao longo da história se iriam cumprir: "Quantas vezes no futuro / Esta cena sublime não voltará a ser representada, /Em Estados ainda por nascer e em línguas ainda ignoradas" (III, i, 112-14). A razão que move o gesto sedicioso e homicida será invocada como o desejo de acabar com a tirania (o cesarismo), o que legitimaria o acto. Mas Shakespeare, seguindo relatos históricos (sobretudo o que Plutarco regista nas suas Vidas paralelas ${ }^{4}$ ), e prolongando a sua reflexão sobre as questões do poder e a legitimidade das insurreições (que mobilizara nas oito peças que antes escrevera sobre a Inglaterra pré-Tudor ${ }^{5}$ ), introduz a interrogação política (na avaliação das consequências) e a problematização trágica (na configuração do herói). E aqui surge a primeira curiosidade: é que o herói trágico desta peça não é o que surge em título, mas antes Bruto, aquele que foi chamado para encabeçar a conspiração dos senadores romanos contra o "ditador perpétuo". De algum modo, a "arrumação" das forças colocava de um lado César, apoiado na "turba" popular (representando o autoritarismo populista), e, do outro, os senadores romanos que representariam os valores da República, integrando uma - aparentemente elevada - reivindicação ética. E é, de resto, inevitável perceber nesta peça de Shakespeare as "correspondências" com o tempo político dos últimos anos do reinado de Isabel I: a ascensão politica do Parlamento (que, quarenta anos mais tarde trará o fim da monarquia Stuart e a instituição da República sob o comando de Cromwell), a força "moralizadora" dos puritanos que dominavam o municipio de Londres (e que execravam festejos e teatros,

considerando-os lesivos para a vida económica e moral), e, claro, a insistente desconfiança quanto à firmeza das inclinações da multidão que passa da idolatria ao ódio em questão de minutos, consoante o brilho oratório de quem a apostrofe.

E estas são questões fundamentais que a crítica shakespeariana sobretudo a partir dos anos 80 do século $X X$ foi, de forma mais minuciosa, analisando e avaliando ${ }^{6}$, acabando por concluir que as estratégias retóricas identificadas nas peças de Shakespeare correspondem aos grandes debates do Renascimento em torno da natureza e da origem do poder político. E será justamente na medida em que esses argumentos políticos são aqui invocados e mobilizados em vividas presentificações cénicas que se reconhece - então como agora - o valor artístico de
Shakespeare. Ignorar esta espessura - histórica, política, ética, humana afinal - é ficar aquém do texto e das suas possibilidades teatrais.

Não foi naturalmente esse o caso de Luís Miguel Cintra, encenador e co-autor da excelente tradução que o espectáculo usou. De facto, na sua reflexão, publicada no programa - "Este espectáculo" -, ele sublinha essa condição e as consequências hermenêuticas que daí derivaram. Mas ao fazê-lo, talvez tenha sido tentado por um cepticismo que pode não fazer justiça em absoluto a uma visão mais rigorosa da coisa histórica que, por exemplo, contemplasse momentos posteriores em que o império (com Augusto) pôde viver um tempo de relativa pacificação e florescimento cultural, ou que integrasse uma visão classista para distinguir os valores de uma aristocracia senatorial e uma certa abertura "democratizante" que o cesarismo ainda propunha (por mais caricata que possa ser na peça a representação da inconstância da turba). Mas é certo que é por esta possibilidade de ainda hoje podermos discutir e avaliar estas coisas - com visões diversas, como é natural - que se expõe o valor da grande arte, a sua infinita capacidade de nos confrontar com questões, imagens e palavras que nos obrigam a sair de nós próprios para entender o mundo, a arte e as paixões que movem a humanidade. Porque sem paixão a vida pode tornar-se bem minguada...

0 que sobressai nesta interpelação da Cornucópia é o escopo amplo e cheio de ressonâncias que adoptou na abordagem deste mundo dramático e que se expunha em três coordenadas principais: a fundação do espaço (e, nele e por ele, as relações várias que propõe), a figuração impressiva (mas não majestosa) daquele universo humano, e a criação de uma atmosfera sonora com um sentido de triste respiração de alma, de desarticulada "harmonia", de cacofonia, enfim.

Do ponto de vista plástico, foi talvez até hoje a intervenção mais ousada e estruturante de Cristina Reis fora do seu espaço próprio e a que, de forma mais feliz, acentuou a realidade própria da Cornucópia num lugar que era do "outro" (o de um teatro municipal, como é o São Luiz), respeitando ambas as formações, e apresentandoas em diálogo. É assim que vemos as estruturas - leves - em palco a sugerirem paredes, portas, colunas ou degraus, em desenhos de uma geometria rigorosa, mas por vezes cortados em oblíquo, e em tons entre o branco e o amarelo torrado, próximo do ocre da bela cidade da Itália. Mas a sala surge na sua realidade própria, mantendo-se visiveis em palco os bastidores e a teia no palco (porque excluidas
${ }^{4} 0$ livro de Plutarco apareceu em 1579 numa versão inglesa de Thomas Norton (a partir da tradução francesa de Jacques Amyot, de 1559). As três "vidas" que a peça de Shakespeare convoca são: Júlio César, Bruto e Marco António.

\section{${ }^{5}$ As duas tetralogias} sobre a história da Inglaterra incluem: Henrique VI (três partes) Ricardo III, Ricardo II, Henrique IV (2 partes) e HenriqueV.

${ }^{6}$ V. Leonard Tennenhouse, Power on Display: The Politics of Shakespeare's Genres, London, Macmillan, 1986. 
A tragédia de Júlio César, de William Shakespeare, enc. Luis Miguel Cintra, Teatro da Cornucópia/ São Luis Teatro Municipal, 2007 (1. ${ }^{\circ}$ acto, cena 3), fot. Paulo Cintra.
A tragédia de Júlio César de William Shakespeare, enc. Luis Miguel Cintra, Teatro da Cornucópial São Luis Teatro Municipal, 2007 (Dinarte Branco e Ricardo Aibéo), fot. Paulo Cintra.

ren

A tragédia de Júlio César, de William Shakespeare, enc. Luis Miguel Cintra, Teatro da Cornucópia/ São Luis Teatro Municipal,

2007 (Dinis Gomes,

Joaquim Horta,

Luis Lima Barreto,

José Manuel Mendes,

Nuno Lopes,

Luis Miguel Cintra,

Pedro Lacerda,

Tonan Quito,

Dinarte Branco,

Teresa Sobral,

Rita Durão

e André Silva),

fot. Paulo Cintra.

${ }^{7}$ Não será dificil

lembrarmo-nos da

figuração dada ao garrettiano Bernardim Ribeiro no espectáculo Um auto de Gil Vicente

(1996).

${ }^{8} \mathrm{Na}$ escola medieval o trivium integrava as disciplinas relativas à eloquência (Gramática, Retórica e Dialéctica), enquanto o quadrivium

compreendia as disciplinas: Aritmética, Geometria, Música e Astronomia.

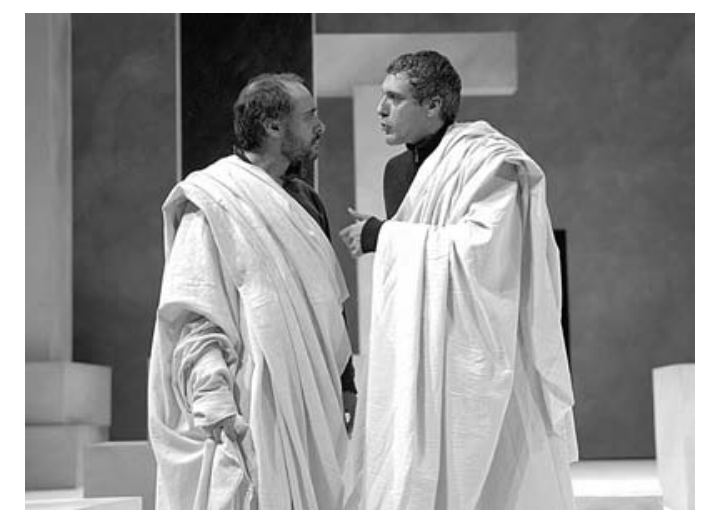

pernas e bambolinas), e permitindo-se uma repetida interrelação, sobretudo quando os actores avançam pela plateia e se "misturam" com os espectadores, como se estivéssemos numa reunião - no fórum - em que todos participássemos.

Na figuração há duas questões dominantes: a assunção de anacronismos nos figurinos, como mistura impura e verdadeira, e um trabalho interpretativo que traz à cena figuras da nossa dimensão, sem hieratismos nem pompa, marcadas antes pelas fissuras que continuamente se abrem no texto de Shakespeare para mostrar cada um como feito de traços contraditórios e num vaivém entre o que cada um pensa de si e o modo como os outros o vêem.

Se na primeira parte do espectáculo (os 3 primeiros actos da peça), os actores envergam, no geral, um fato neutro escuro em cima do qual colocam o manto romano (ou toga), na segunda - que decorre em contexto de guerra -, são inicialmente os fatos de executivo para o novo triumvirato e, depois, os camuflados que tomam a dianteira. Mas, em ambas as situações cénicas, introduzem-se elementos figurativos disruptivos, por vezes apenas para destacar algum elemento, outras para construir uma imagem enigmática de sentido simbólico. Na 1. ${ }^{\text {a }}$ parte, a par do destaque dado aos elementos carnavalescos das máscaras populares (numa curiosa aparência pop) e do fato de treino do favorito de César que correria na Lupercália, assinalem-se as capas negras e chapéus de abas largas para os conspiradores (em perfil que poderia ser do séc. XVII, do tempo dos espadachins, ou romântico ${ }^{7}$ ), mas sobretudo a figura enigmática de Artemidoro (por Nuno Gil): vestido de negro, elegante nas suas meias altas, sapatos com tacão e laçarote, calções em balão.

Caminhando de forma compassada, levantando por vezes uma perna como um flamingo, a mão posta à altura da cintura nas costas, recuando por vezes, sempre numa atitude assumidamente elaborada. Poderá ser lida esta
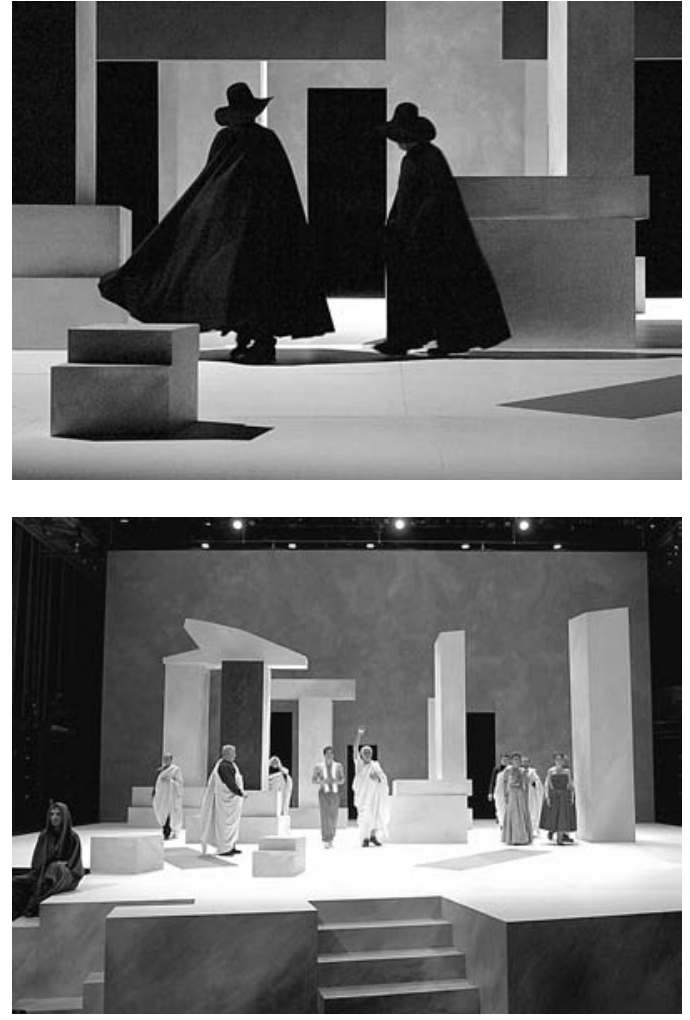

imagem como o tempo trágico, o recorte de um homem de quinhentos ou seiscentos, o próprio bardo em marcação lutuosa. Mas atentando no facto de ser "professor de retórica", à convergência com a própria figuração de um Shakespeare simbólico, acrescentar-se-iam os ademanes próprios desta disciplina do trivium $^{8}$. Na segunda parte, para além do ostensivo anacronismo das espadas na relação com os camuflados, é sobretudo a figura trazida à boca de cena (à esquerda) por Dinis Gomes que concita a estranheza: sentado displicentemente, de costas para a dor da batalha, fuma calmamente, como admitindo a "normalidade" daquele caos num mundo que se organiza em termos militares. Mas para além da relação contrastriva com o que ocorre em cena, a figura apela a uma memória da 1. a parte do espectáculo: o mesmo actor - de figura cada vez mais magra e esguia - fora o adivinho que lembrara a César o perigo dos Idos de Março. Assim sendo, poderíamos ver na sua segunda figuração a invetivável consequência do acto sedicioso.

Este espectáculo, que pôde contar com um elenco alargado, mantinha nos papéis principais alguns dos actores que há já algum tempo estão ligados à Cornucópia, com destaque maior para Rita Durão, como uma Pórcia feita de frémito apaixonado e de força moral que, de forma fulgurante, traz à cena. Luis Lima Barreto, tornando - com acerto - o seu Casca uma figura quase vaudevilesca, Nuno Lopes conseguindo por vezes um brilho invulgar durante o discurso fúnebre -, Ricardo Aibéo como um magnífico Cássio (mas desacertado do diagnóstico de César que o faz magro), José Manuel Mendes soberbo na figura do velho que vem dizer uma quadra, Luís Lucas de uma elocução irrepreensivel, e Teresa Sobral figurando com rigor uma Calpúrnia receosa da sorte de César. Numa questão só julgo que o espectáculo não terá cumprido em termos figurativos - as potencialidades teatrais do texto shakespeariano, uma vez que me parece que Bruto 


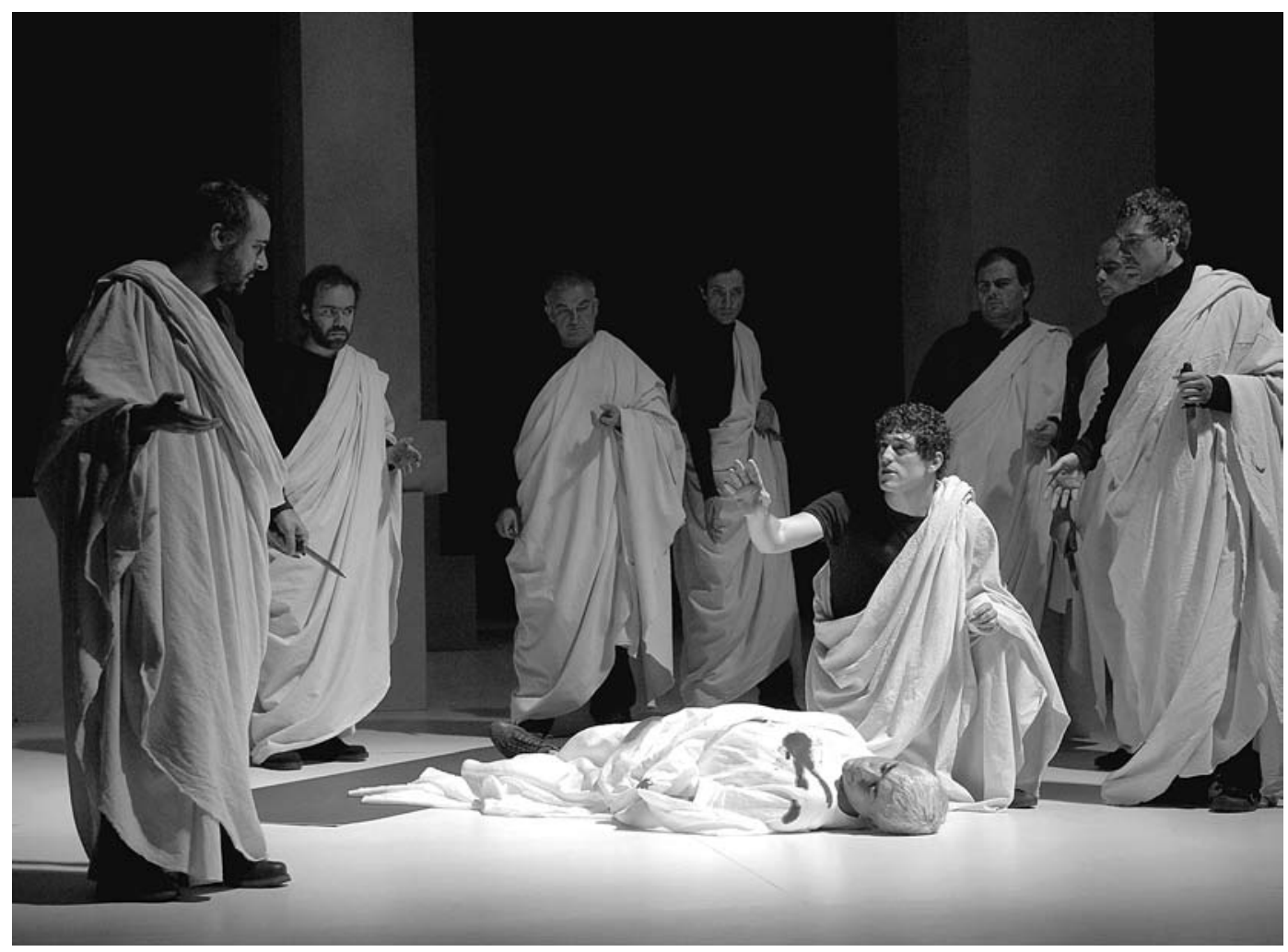

A tragédia de Júlio César de William Shakespeare, enc. Luis Miguel Cintra, Teatro da Cornucópia/ São Luis Teatro Municipal, 2007 (Dinarte Branco, Tonan Quito, Luis Lima Barreto, Pedro Lacerda, Ivo Alexandre, Joaquim Horta e Ricardo Aibéo; em baixo: Luis Miguel Cintra e Nuno Lopes), fot. Paulo Cintra

teria de ter uma presença mais carismática, mais consistente na sua força ética, de um fulgor moral contido mas persuasivo. E Dinarte Branco mostra-se por demais introspectivo, fraco na consistência das suas certezas, de elocução pouco enérgica e de presença débil na relação com os outros. Que a figura trágica fosse percorrida de dúvidas e assaltada por uma enorma angústia, não haveria dúvida (será, de resto, na dramaturgia de WS um primeiro esboço de Hamlet); mas, no contorno que o palco Ihe dá, torná-lo o objecto das apóstrofes tão elogiosas que todos Ihe dirigem torna-se um pouco inverosimil. Luis Miguel Cintra, de forma brilhante, constrói um César demasiado humano, vaidoso e desbragado, como Shakespeare o compõe a partir de três "vidas paralelas" de Plutarco, mas a que o dramaturgo adiciona mais fraquezas e ridicularias para o tornar um pouco bufão.

Ainda num aspecto de desenho figurativo, poder-seia questionar o aparecimento do "fantasma" de César antes da batalha de Filipos. Sabemos que muitos autores e encenadores se têm interrogado - e interrogam - sobre a forma mais efectiva de pôr em cena figuras fantasmáticas, tendo T. S. Eliot (a propósito de Family Reunion) e Craig (a propósito do sobrenatural em Shakespeare), por exemplo, sugerido que elas não deveriam ser vistas em cena, mas tão só sugeridas por uma inesperada ausência ou através de efeitos sonoros ou de luz. Neste espectáculo, verificase que a opção feita sublinha uma vez mais a importância dada à dimensão exacta do corpo humano e da sua proximidade - num projecto de assumida artesania teatral - com a consequente perda do que pudesse ser o horror de culpa de Bruto.

A música - de Vasco Mendonça - executada ao vivo através de trompete, percussão e guitarra traz a confusão e distopia que marcam a acção, sobretudo os conflitos bélicos que nos dois últimos actos vêm "provar" a inevitabilidade do caos, o que, em termos de composição cénica, se expõe no palco esvaziado, cena escura e luz azul forte. E os traços que Cintra e Cristina Reis trouxeram àquele lugar de guerra vêm marcados pela proximidade histórica - em termos de figurinos (camuflados) e de adereços - pelo que o sabor triste daquela desordem parece legitimar o desalento do encenador quando escreve no programa que a peça "mostra a coragem de um grupo que tentou dar à sua pátria a liberdade", mas que é de desfecho trágico inevitável essa pretensão porque "não se pode ser justo num mundo injusto". Que todas as certezas são lugares mais do que provisórios da afirmação humana, não temos dúvida, mas admitir que nada se pode fazer para alterar o mundo também seria rasurar a história, injustiçar o esforço de muitos e, sobretudo, permitir o avanço do pior.

E é justamente isso que Luis Miguel Cintra não faz: porque quem encena tão apaixonadamente, e de forma tão arrebatadora uma peça complexa e exigente como esta, está justamente a demorar-se naquele lugar que é "provisório", mas que tem um longo futuro na vida dos homens.

\section{Referências bibliográficas}

CRAIG, Edward Gordon (1980), "On the ghosts in the tragedies of Shakespeare", On the Art of the Theatre (1911), London, Heinemann, pp. 264-280.

ELIOT, T.S. (1950), "The Family Reunion", in Playwrights on Playwriting (1961), Eds. Toby Cole, New York, Hill \& Wang, pp. 254-255.

SAMUEL, Raphael / MacCOLL, Ewan / COSGROVE, Stuart (1985), Theatres of the Left 1880-1935: Workers' Theatre Movements in Britain and América, London, Routledge \& Kegan Paul.

TENNENHOUSE, Leonard (1986), Power on Display: The Politics of Shakespeare's Genres, London, Macmillan. 